\title{
EXPERIMENTAL DERMATOPHYTOSIS IN HAMSTERS INOCULATED WITH Trichophyton mentagrophytes IN THE CHEEK POUCH
}

\author{
Maria Sueli Parreira de ARRUDA(1), Silvia GILIOLI(1) \& Fátima Regina VILANI-MORENO(2)
}

\begin{abstract}
SUMMARY
This study presents the results of $T$. mentagrophytes inoculation in the cheek pouch of the hamster, an immunologically privileged site. Forty two animals were used: 21 inoculated with $10^{6}$ fungi in the cheek pouch (group 1) and 21 inoculated initially with $10^{6}$ fungi in the foot pad and 15 days later in the cheek pouch, with the same amount of fungi (group 2). Animals were sacrificed at 20 hours, 3, 7, 14, 30, 60, and 120 days; samples from inoculated cheek pouch, and foot pads submitted to the foot pad test (FPT), were collected. Independent of group and time of evolution of infection, animals did not develop delayed hypersensitivity evaluated through the FPT. The pre-inoculation of fungi in the foot pad did not change the morphology of lesions induced in the cheek pouch. Therefore, in animals of group 1 and 2, the introduction of the fungus in the cheek pouch resulted in focal lesion composed of a sterile acute inflammatory infiltrate, with abscess formation that evolved to a macrophagic reaction, and later to resolution even in the absence of immune response detectable by FPT. Our results indicate that in spite of the important role of the immune response in the spontaneous regression of dermatophytosis, other factors are also an integral part in the defense against this fungal infection.
\end{abstract}

KEYWORDS: Experimental dermatophytosis; Trichophyton; Cheek pouch; Hamster.

\section{INTRODUCTION}

Dermatophytes are a group of highly specialized fungi which, throughout a long evolutionary process, have became able to invade, colonize and maintain themselves in keratinized tissues. These organisms are divided in 3 genders: Trichophyton (T), Microsporum, and Epidermophyton, that can induce a variety of inflammatory reactions ${ }^{15}$. Different from other pathogenic fungi, dermatophytes are not opportunists and frequently infect health individuals. In the same way, different from opportunist microorganism that can disseminate in immunosuppressed hosts, dermatophytes are unable to cause systemic infection $^{23}$. Therefore, these fungi seem to develop a special interaction with the immune system. Any data that help us to make this interaction clear, will also contribute for the better understanding of defense mechanisms in mammals.

In general, studies aiming to investigate the role of immune response in the control or modulation of dermatophytosis suggest that resistance to this infection occur during the course of the primary disease, and is associated to development of delayed hypersensitivity and T lymphocyte activation $^{3}$. Particularly with respect to Trichophyton, it has been reported that this fungus may induce both immediate hypersensitivity and delayed hypersensitivity (DH). The nature of the response evoked has been related to the ability of the organism to eliminate the fungus. That is why the presence of DH has been associated with acute and highly inflamed lesions, while chronic infections are common in individuals with positive immediate hypersensitivity ${ }^{23}$.

Experimentally, TAGAMI et al. ${ }^{20}$ described that guinea-pigs inoculated with T. mentagrophytes exhibit a maximum degree of erythema and infiltrate at the inoculation site between the $9^{\text {th }}$ and $14^{\text {th }}$ day of the development of $\mathrm{DH}$; after that there was regression. Four weeks later lesions were healed. When animals were re-infected with $T$. mentagrophytes, peak of lesions occurred 2 days after re-infection and lesions regressed within 10 days, which suggests the participation of the immune response in the resolution of lesions.

Considering that experimental studies focused on dermatophyte-host interactions are scarce, and aiming a better understanding of this relationship, we investigated the development of infection induced by $T$. mentagrophytes in the cheek pouch of the hamster, an immunologically privileged site, in prime-infected animals, as much as in animals inoculated initially in the foot pad and later re-inoculated in the cheek pouch.

\section{MATERIAL AND METHODS}

Inoculum: suspensions of $T$. mentagrophytes from the fungal collection of the Institute "Lauro de Souza Lima", Bauru, São Paulo, were used. Fungi were cultured in Micosel medium (Difco Lab., Detroit, Michigan, USA), for 15 days at $25^{\circ} \mathrm{C}$. The viability of the fungus was

(1) Biological Science Department, School of Science, UNESP/Bauru, SP, Brasil.

(2) Immunology Section, Institute "Lauro de Souza Lima", Bauru, SP, Brasil.

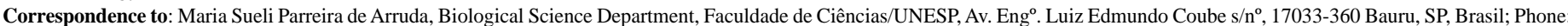
55.14.230-6166, e-mail: sueli@fc.unesp.br 
determined by the cotton blue staining and the final concentration adjusted to $10^{7}$ viable $T$. mentagrophytes $/ \mathrm{ml}$.

Animals: 42 male hamsters, 2 month-old, from the Animal House at UNESP-Botucatu. They were divided at ramdon in two groups: the Experimental Group 1 (G-1), composed of 21 hamsters inoculated with $10^{6}$ viable fungi in the distal portion of the right cheek pouch, and Experimental Group 2 (G-2), composed of 21 hamsters previously inoculated with $10^{6}$ viable fungi in the left foot pad, and 15 days later inoculated in the right cheek pouch with the same amount of fungi. A minimum of 3 animals per group were sacrificed at 20 hours and at 3,7 , 14, 30, 60 and 120 days post-inoculation in the cheek pouch. After sacrifice, samples of inoculated cheek pouch were submitted to routine protocols paraffin inclusion and hematoxilin-eosin (HE) and/or methenamine silver stainings ${ }^{9}$.

Immunological evaluation: the development of specific cellular immune response was evaluated through the foot pad test (FPT), as proposed KONG et al..$^{12}$, and modified as follows: $0.1 \mathrm{ml}$ of trichophytin (Alerbrás, Rio de Janeiro, Brazil) was injected in the right foot pad 24 hours before the sacrifice, the foot was then excised and fixed in $10 \%$ formaldehyde. After fixation, the foot was demineralized in $25 \%$ nitric acid and $25 \%$ formaldehyde 1:1, and submitted to routine procedures for paraffin inclusion and $\mathrm{HE}$ staining.

\section{RESULTS}

Lesions of inoculation were observed until the $30^{\text {th }}$ day after introduction of the fungus in the cheek pouch of animals inoculated only in the cheek pouch (G-1) and, until the $15^{\text {th }}$ day in animals inoculated first in the foot pad, and later in the cheek pouch (G-2).

Histologically, except for the greater exuberance of lesions, preinoculation of the fungus in the foot pad has not affected the morphology of lesions induced in the cheek pouch at any time of the experiment. Therefore, after 24 hours, animals of groups 1 and 2 showed a focal cluster of neutrophils at the inoculation site, without fungi detectable by HE or methenamine silver staining. Neutrophils, many of them degenerated, compressed the conjunctive layer of the dermis that presented a few mononuclear cells (Figure 1). In animals of group 2, the interstitial infiltrate was more intense and diffuse, spreading beyond the supurative foci. At 3 days, the process had not changed; nonetheless, there was a large number of mononuclear cells in the periphery of lesion, mainly in animals of G-2.

On the $7^{\text {th }}$ day, the abscess presented the same characteristics as observed in the previous period, however, at the limit between the abscess and the conjunctive tissue of the dermis, the amount of mononuclear cells was larger than observed at 3 days. Some macrophages were vacuolated. Proliferation of vessels, young fibroblasts and increased interstitial collagen, could already been observed in this period, especially in animals of G-2 (Figure 2).

At 15 days, lesions were composed of enlarged macrophages, many of them vacuolated, giving a lacy aspect to the cytoplasm. Lesions had precise limits and exhibited hyalinized collagen, dense mononuclear infiltrate and some plasm cells at the periphery (Figure 3). There were no other differences between the two studied groups.

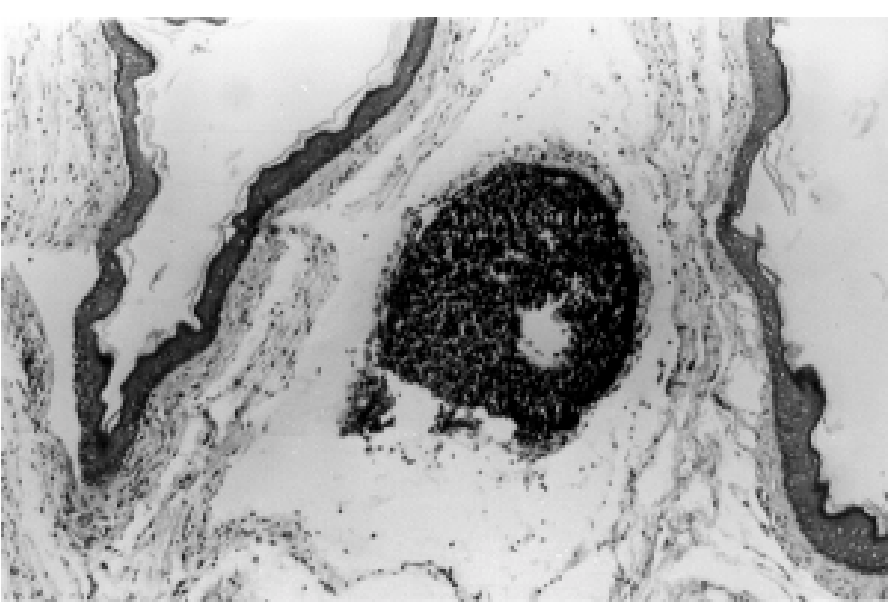

Fig. 1 - Cheek pouch. 24 hours. Group 1. Lesion of inoculation. Neutrophil infiltrate forming abscess (HE - 100X).

A

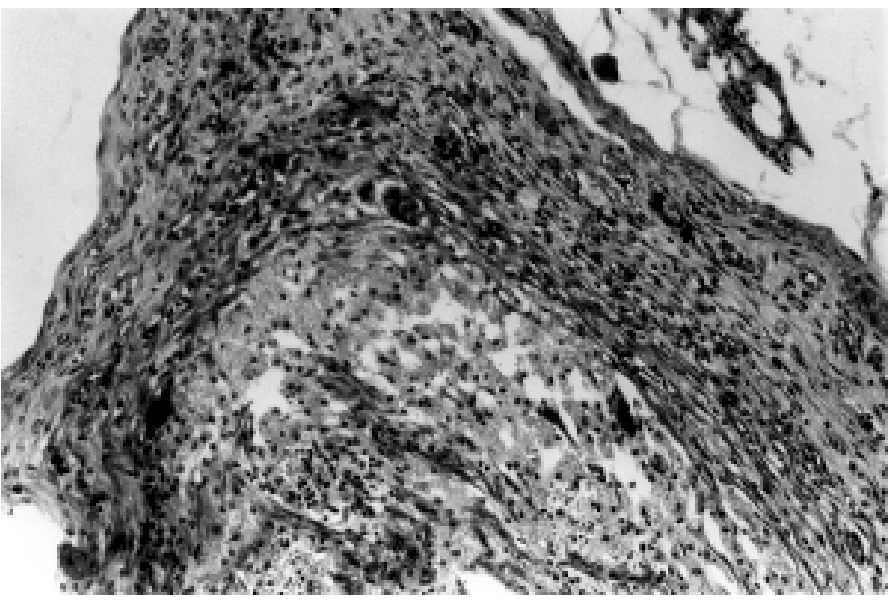

B

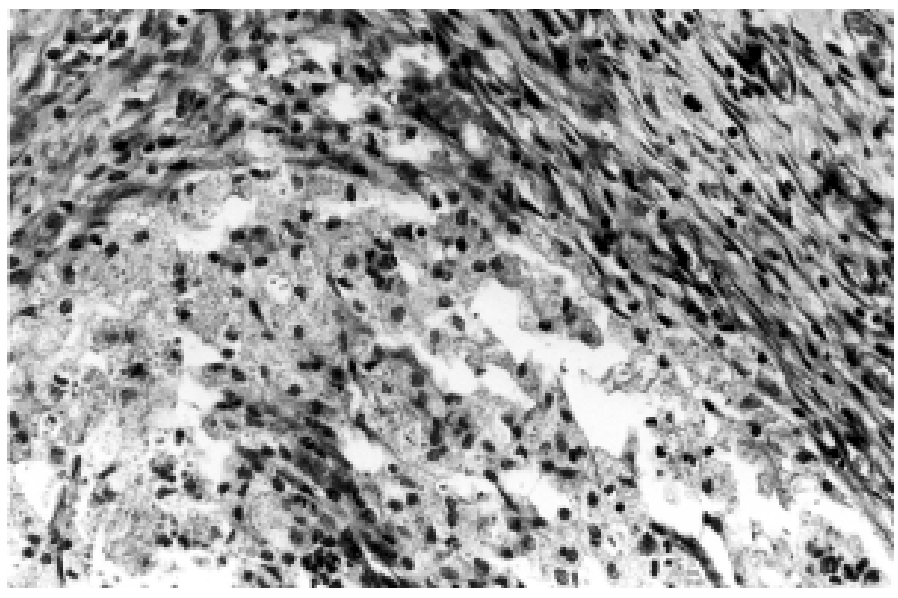

Fig. 2 - Cheek pouch. 7 days. Group 1. Lesion of inoculation. A- Edge of the abscess: notice enlarged macrophages, with abundant cytoplasm and multivacuolated; a better composition of the abscess wall, with proliferation of vessels and collagen deposition (HE - 200X). BDetail of previous figure (HE - 400X). 


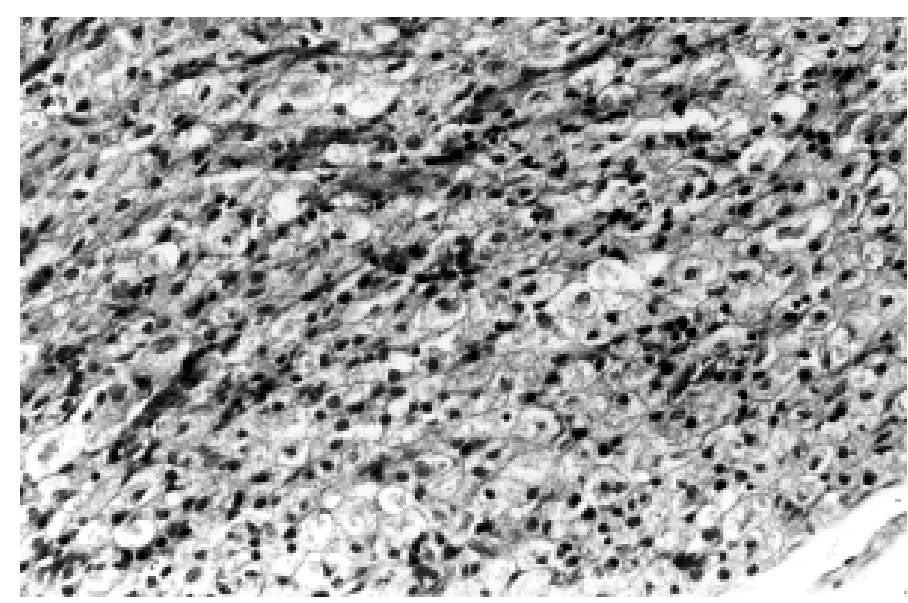

Fig. 3 - Cheek pouch. 15 days. Group 2. Lesion of inoculation. Macrophagic infiltrate, many of them containing vacuoles in the cytoplasm (HE -200X).

At 30 days, lesions were observed only in G-1. These were characterized by a small clustering of mononuclear cells in the dermis. After that, lesions of inoculation could no longer be detected.

No animal presented change of volume of the tested foot when compared to the opposing foot. In the same way, at histopathology the tested foot pads did not show changes characteristic of the DH reaction, therefore, all animals were considered FPT negative.

\section{DISCUSSION}

The development of DH against dermatophyte antigens has been documented in humans and some animal species. Cutaneous reactivity to trichophytin antigen extracted from fungal cultures, has been described in dermatophytosis patients, even in those with severe infections ${ }^{20}$. Experimentally, guinea pigs inoculated with $T$. mentagrophytes are positive in the intradermic test with trichophytin between the $7^{\text {th }}$ and $9^{\text {th }}$ days after inoculation ${ }^{11}$. Similarly, rabbits presented positive response to the leukocyte migration inhibition test (MIF), after the second week of inoculation of the fungus ${ }^{5,7}$.

In the present study, however, regardless of the site of inoculation and time of evolution of infection, animals showed to be non reactors to the trichophytin antigen, evaluated by FPT. The absence of specific DH in hamsters inoculated only in the cheek pouch (G-1) could be related to the fact that this structure lacks lymphatic drainage, and consequently, there is confinement of T. mentagrophytes to the inoculation site, as observed in other fungi ${ }^{1}$ and mycobacteria ${ }^{16}$. Nonetheless, hamsters inoculated in the foot pad, area plenty of lymphatic vessels, have also shown to be nonreactors. It is possible then that in these animals, similar to what happens with T. rubrum, T. mentagrophytes has induced release of suppressor cells and/or factor, which inhibited development of cellular immune response $e^{4,10}$.

On the other hand, the animals used in this study, specially those previously inoculated in the foot pad, may have developed immune response undetectable by the performed method.

The evaluation of the specific cellular immune response in dermatophyte inoculated animals has been done by subcutaneous tests, and by in vitro blastic transformation and MIF techniques; regardless of KERBS et al. ${ }^{11}$ have obtained equivalent results, other authors described dissociation between these techniques ${ }^{2,6,11,13}$. According to REZKALLAH-IWASSO et $a l .{ }^{14}$, this dissociation could be explained by the proportion of cells and/or mediators involved in the different types of response. For SOARES ${ }^{17}$ these tests could involve distinct cellular subpopulations that could be under different regulatory effects.

In vitro experiments have also demonstrated that the type of antigen utilized may interfere on detection of immune response. Therefore, ELEUTÉRIO et $a l .{ }^{5}$ and GARCIA DE LOMAS et $a l .^{7}$ observed that rabbits inoculated with $T$. mentagrophytes presented cellular immune response against the fungus, detected by the MIF, using an antigen composed of keratinase plus mycelial antigen, but did not present response with trichophytin. Opposed to that, KERBS et al. ${ }^{11}$, using the blastic transformation method, verified that guinea-pigs experimentally infected with $T$. mentagrophytes exhibited positive response only when trichophytin antigen was used.

Added to this, observations related to human dermatophytosis are found; it has been suggested that in patients with dermatophytosis, the negative reaction to trichophytin would be related to development of IgE antibodies; these antibodies could deplete available fungal antigens by binding to them, or form complexes that would affect the manifestation of DH response $\mathrm{e}^{21,22}$.

These data became relevant when the histological result obtained from the two groups studied were confronted: animals previously inoculated in the foot pad showed more exuberant lesions in the cheek pouch and shorter time for resolution, compared with the observed in animals inoculated only in the cheek pouch. Similar results were described by TAGAMI et al. ${ }^{19}$, when guinea-pigs were inoculated with T. mentagrophytes: lesions of inoculation resolved faster in sensitized animals than in non sensitized. In face of this, other studies are needed to clearly determine if hamsters inoculated in the foot pad do not develop cellular immune response when challenged T. mentagrophytes.

In spite of that, except for the marked exuberance of lesions in animals of G-2, the inoculation of fungus in the foot pad has not affected the morphology of lesions induced by Trychophyton in the cheek pouch. In animals of groups 1 and 2, lesions are initially characterized by the presence of sterile, acute inflammatory infiltrate, with abscess formation that evolved to a macrophagic reaction, and later to resolution. The presence of these abscesses could be a consequence of the fungal components over the complement system, once it has been reported that $T$. mentagrophytes activates this system generating anaphylotoxin C5a, even in non immune animals, through the alternate via ${ }^{18}$. This hypothesis is supported by the fact that patients with disseminated dermatophytosis frequently present pustules. Many of these patients do not have cell-mediated immunity against Trichophyton antigens and do not develop $\mathrm{DH}$ evaluated through the intradermic test with trichophytin. It has also been suggested in these cases that polymorphonuclear cells migrate to the area of follicle rupture after complement activation and C5a generation ${ }^{3}$. Besides C5a, soluble factors released by keratinocytes, including $I L 8$, have also been involved in this process ${ }^{3,10}$.

The role of neutrophils in the defense mechanisms against dermatophytes is not totally clear. It has been demonstrated in experimental models that neutrophil infiltration occurs before the peak of infection ${ }^{23}$ 
and these are capable of inhibiting fungal multiplication, even in the absence of immune response $e^{8,10}$.

In the present study, regardless of the group studied, lesions evolved to resolution. In animals inoculated only in the cheek pouch, resolution occurred later than it observed in animals initially inoculated in the foot pad, and later in the cheek pouch. Similar results were observed by TAGAMI et al. ${ }^{20}$, in leukopenic animals. These authors demonstrated that in immune animals, as much as non immune, the time required for lesions to resolve was longer when leukopeny was induced concomitantly with inflammation. The delayed cure was more noticeable in non immune animals. Our results, associated to these, indicate that in spite of the important role of the immune response in the spontaneous regression of dermatophytosis, other factors are also an integral part in the defense against this fungal infection.

\section{RESUMO}

\section{Dermatofitose experimental do hamster inoculado com Trychophyton mentagrophytes na bolsa jugal}

Esse estudo apresenta os resultados obtidos quando da inoculação de Trychophyton mentagrophytes na bolsa jugal do hamster, local imunologicamente privilegiado. Foram utilizados 42 animais: 21 inoculados com $10^{6}$ fungos na bolsa jugal (grupo 1) e, 21 inicialmente inoculados com $10^{6}$ fungos no coxim plantar e, 15 dias após, na bolsa jugal com a mesma quantidade fúngica (grupo 2). Os animais foram sacrificados às 20 h, 3, 7, 14, 30, 60 e 120 dias; foram coletadas amostras da bolsa jugal inoculada, e das patas submetidas ao teste do coxim plantar (TCP). Independente do grupo e do tempo de evolução da infecção, os animais não desenvolveram hipersensibilidade tardia avaliada através do TCP. A pré-inoculação de fungos no coxim plantar não alterou a morfologia das lesões induzidas na bolsa jugal. Assim, nos animais do grupo 1 e grupo 2, a introdução do fungo na bolsa jugal, resultou em lesão focal, constituída por infiltrado inflamatório agudo estéril, com formação de abscesso, que evoluiu para reação macrofágica e, posteriormente, para a resolução mesmo na ausência de resposta imune detectável pelo TCP. Nossos resultados indicam que, apesar do importante papel da resposta imune na regressão espontânea da dermatofitose, outros fatores são, também, parte integral da defesa contra esta infecção fúngica.

\section{REFERENCES}

1. ARRUDA, M.S.P. \& MONTENEGRO, M.R. - The hamster cheek pouch: an immunologically privileged site suitable to the study of granulomatous infections. Rev. Inst. Med. trop. S. Paulo, 37: 303-309, 1995.

2. CHAPARAS, S.D.; GOOD, R.D. \& JANICKI, B.W. - Tuberculin-induced lymphocyte transformation and skin reactivity in monkeys vaccinated or not vaccinated with bacille Calmette-Guerin, then challenged with virulent Mycobacterium tuberculosis. Amer. Rev. resp. Dis., 112: 43-47, 1975.

3. DAHL, M.V. - Dermatophytosis and the immune response. J. Amer. Acad. Derm., 31(suppl.): S34-S41, 1994.

4. DAHL, M.V. - Suppression of immunity and inflammation by products produced by dermatophytes. J. Amer. Acad. Derm., 28(suppl.): S19-S23, 1993.

5. ELEUTÉRIO, M.K.; GRAPPEL, S.F.; CAUSTIC, C.A. \& BLANK, F. - Role of keratinases in dermatophytosis. 3. Demonstration of delayed hypersensitivity to keratinases by the capillary tube migration test. Dermatológica, 147: 255-260, 1973.
6. FULTON, A.M.; DUSTOOR, M.M.; KASINSKI, J.E. \& BLAZKOVEC, A.A. Blastogenesis as an in vitro correlate of delayed hypersensitivity in guinea pigs infected with Listeria monocytogenes. Infect. Immun., 12: 647-655, 1975.

7. GARCIA DE LOMAS, J.; RODRIGUEZ, F.; CAVAS, M.L.; LOPEZ, I. \& ALTUNA, A. - Immunology of dermatophytosis. Experimental study. Mycopathologia (Den Haag), 82: $29-32,1983$.

8. GRAPPEL, S.F.; BISHOP, C.T. \& BLANK F. - Immunology of dermatophytes and dermatophytosis. Bact. Rev., 38: 222-250, 1974.

9. GROCOTT, R.G. - A stain for fungi in tissue sections and smears using Gomori's methenamine-silver nitrate technic. Amer. J. clin. Path., 25: 975-979, 1955.

10. JONES, H.E. - Immune response and host resistence of humans to dermatophyte infection. J. Amer. Acad. Derm., 28(suppl.): S12-S18, 1993.

11. KERBS, S.; GREENBERG, J. \& JESRANI, K. - Temporal correlation of lymphocyte blastogenesis, skin test responses and erythema during dermatophyte infections. Clin. exp. Immunol., 27: 526-530, 1977.

12. KONG, Y.M.; SAVAGE, D. \& KONG, L.N.L. - Delayed dermal hypersensitivity in mice to spherule and mycelial extracts of Coccidioides immitis. J. Bact., 91: 876-883, 1966.

13. OPPENHEIM, J.J. - Relationship of in vitro lymphocyte transformation to delayed hypersensitivity in guinea pigs and man. Fed. Proc., 27: 21-28, 1968.

14. REZKALLAH-IWASSO, M.T.; MOTA, N.G.S.; GOMES, M.C.G. \& MONTENEGRO, M.R.G. - Effect of levamisole on experimental paracoccidioidomycosis in the Syrian hamster: immunologic and histopathologic correlation. Mycopathologia (Den Haag), 84: $171-180,1984$

15. SAN-BLAS, G. - The cell wall of fungal human pathogens: its possible role is hostparasite relationships. Mycopathologia (Den Haag), 79: 159-184, 1982.

16. SINHORINI, I.L.; MERUSSE, J.L. \& MARIANO, M. - Role of lymphatic drainage on the development of Calmette-Guérin bacillus-induced granulomas in the hamster. Int. Arch. Allergy Immunol., 103: 166-174, 1994.

17. SOARES, A.M.V.C. - Cinética e imunomodulação da resposta inflamatória granulomatosa na infecção endovenosa experimental por Paracoccidioides brasiliensis, do camundongo. Ribeirão Preto, 1986. (Tese de Doutoramento Faculdade de Medicina da Universidade de São Paulo).

18. SWAN, J.W.; DAHL, M.V.; COPPO, P.A. \& HAMMERSCHMIDT, D.E. - Complement activation by Trychophyton rubrum. J. invest. Derm., 80: 156-158, 1983.

19. TAGAMI, H.; WATANABE, S. \& OFUJI, S. - Trichophytin contact sensitivity in guinea pigs with experimental dermatophytosis induced by a new inoculation method. J. invest. Derm., 61: 237-241, 1973.

20. TAGAMI, H.; KUDOH, K. \& TAKEMATSU, H. - Immune defense mechanisms in dermatophytosis. In: INTERNATIONAL SYMPOSIUM OF THE RESEARCH CENTER FOR PATHOGENIC FUNGI AND MICROBIAL MYCOSIS, 4., Chiba Univ., 1989. Proceedings. p. 119-122.

21. VILANI-MORENO, F.R. \& ARRUDA M.S.P. - Contribuição ao estudo da reação à tricofitina nas dermatofitoses. Rev. Inst. Med. trop. S. Paulo, 34: 505-509, 1992.

22. WANKE, N.C.F. \& FRAGA, S. - O teste da tricofitina como subsídio diagnóstico nas dermatofitoses. An. bras. Derm., 52: 7-23, 1977.

23. WOODFOLK, J.A. \& PLATTS-MILLS, T.A.E. - The immune response to dermatophytes Res. Immunol., 149: 436-445, 1998.

Received: 11 May 2000

Accepted: 09 October 2000 